\title{
Retraction Note: Regional air pollution monitoring and aviation service management optimization based on multi-source remote sensing images
}

\author{
Ling Hong ${ }^{1} \cdot$ Weiguo Chen $^{2}$ \\ Published online: 9 November 2021 \\ (c) Saudi Society for Geosciences 2021
}

Retraction Note: Arabian Journal of Geosciences (2021) 14: 1041

https://doi.org/10.1007/s12517-021-07353-3

The Editor-in-Chief and the Publisher have retracted this article because the content of this article is nonsensical. The peer review process was not carried out in accordance with the Publisher's peer review policy. Author Weiguo Liu has not responded to correspondence regarding this retraction. The publisher has not been able to obtain a current email address for author Ling Hong.

The original article can be found online at https://doi.org/10.1007/ s12517-021-07353-3.

Weiguo Chen

hongling8517@163.com

1 College of Tourism Management, Wuhan Business University, Wuhan 430056, Hubei, China

2 Design and Research Institute, Wuhan University of Technology, Wuhan 430070, Hubei, China 